\title{
Strategies to counter antipsychotic-associated weight gain in patients with schizophrenia
}

DOI:

10.1080/14740338.2019.1674809

\section{Document Version}

Accepted author manuscript

Link to publication record in Manchester Research Explorer

\section{Citation for published version (APA):}

Marteene, W., Winckel, K., Hollingworth, S., Kisely, S., Gallagher, E., Hahn, M., Ebdrup, B. H., Firth, J., \& Siskind, D. (2019). Strategies to counter antipsychotic-associated weight gain in patients with schizophrenia. Expert Opinion on Drug Safety, 18(12), 1149-1160. https://doi.org/10.1080/14740338.2019.1674809

\section{Published in:}

Expert Opinion on Drug Safety

\section{Citing this paper}

Please note that where the full-text provided on Manchester Research Explorer is the Author Accepted Manuscript or Proof version this may differ from the final Published version. If citing, it is advised that you check and use the publisher's definitive version.

\section{General rights}

Copyright and moral rights for the publications made accessible in the Research Explorer are retained by the authors and/or other copyright owners and it is a condition of accessing publications that users recognise and abide by the legal requirements associated with these rights.

\section{Takedown policy}

If you believe that this document breaches copyright please refer to the University of Manchester's Takedown Procedures [http://man.ac.uk/04Y6Bo] or contact uml.scholarlycommunications@manchester.ac.uk providing relevant details, so we can investigate your claim.

\section{OPEN ACCESS}




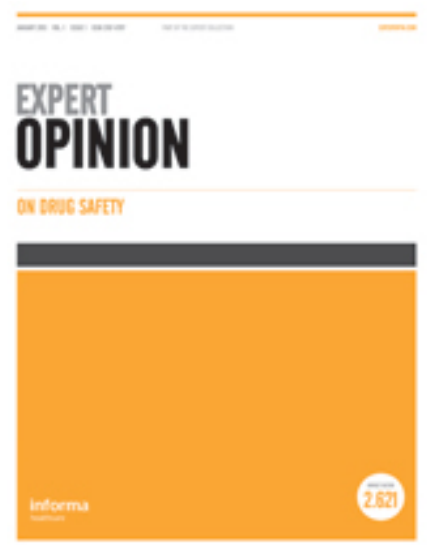

Please download and read the instructions before proceeding to the peer review

\section{Strategies to counter antipsychotic-associated weight gain in patients with schizophrenia}

\begin{tabular}{|r|l|}
\hline Journal: & Expert Opinion On Drug Safety \\
\hline Manuscript ID & Draft \\
\hline Manuscript Type: & Original Research \\
\hline Keywords: & $\begin{array}{l}\text { antipsychotic, lifestyle, mechanisms, obesity, pharmacological, } \\
\text { schizophrenia, weight gain, switching }\end{array}$ \\
\hline
\end{tabular}

\section{SCHOLARONE \\ Manuscripts}




\section{Abstract \\ Introduction}

Patients living with schizophrenia have a marked risk of clinically significant weight gain and obesity compared to the general population. The risks have been highlighted following the introduction of second-generation antipsychotics. In turn, obesity is associated with a higher prevalence of cardiovascular disease, the most common cause of premature mortality in patients with schizophrenia.

\section{Areas Covered}

In this review we outline possible mechanisms that induce obesity in patients with schizophrenia taking antipsychotics. We discuss the safety and effectiveness of three main approaches for attenuating antipsychotic-associated weight gain (AAWG), including lifestyle interventions, switching antipsychotics, and augmentation with other medications.

\section{Expert Opinion}

When selecting antipsychotics, effective treatment of psychotic symptoms should be highest priority but obesity, and related metabolic comorbidities associated with antipsychotics, should not be neglected. Further research into mechanisms of weight gain associated with antipsychotics will guide future treatments for AAWG and development of antipsychotics that produce minimal metabolic adverse effects. With current strategies only producing modest weight loss in already overweight and obese individuals, clinicians should transition to an approach where they aim to prevent weight gain when initiating antipsychotic treatment.

Keywords: antipsychotic, lifestyle, mechanisms, obesity, pharmacological, schizophrenia, weight gain, switching 


\section{Article Highlights}

- The introduction of second-generation antipsychotics has resulted in higher incidences of metabolic risk factors, specifically obesity.

- The mechanisms responsible for antipsychotic-induced weight gain are believed to be changes in hormones and peptides involved in energy homeostasis, antagonism of receptors in appetite and satiety centres, and pharmacogenetic differences between patients. Additionally, recent research has demonstrated a possible role of the gut microbiome.

- Lifestyle interventions including exercise, nutritional advice, and cognitive-behavioural therapy have shown modest reductions in weight gain. However, to be effective such interventions must be adequately designed and resourced in order to promote adherence and lifestyle changes in this population.

- Switching to antipsychotics with a lower risk of inducing weight gain such as aripiprazole, ziprasidone and amisulpride may show promise but applicability is limited by poorly designed studies with high discontinuation rates (largely due to symptom exacerbation).

- Augmentation with other medications is an effective strategy. Metformin and GLP-1RAs have the most robust data demonstrating favourable reductions in weight and minimal reports of serious side effects. 


\subsection{Introduction}

Cardiovascular disease (CVD), is the largest contributor to the 2-3-fold increased mortality rate and disparity in life expectancy of 10-20 years in patients with schizophrenia compared to the general population.[1-3] The prevalence of CVD in patients with schizophrenia is estimated to be $11.8 \%$ with an incidence of $3.6 \%$ per year.[1] It is therefore imperative that clinicians manage CVD-modifiable risk factors including obesity, dyslipidaemia, hypertension, diabetes, and smoking.[4] Obesity is highly prevalent with studies suggesting up to $60 \%$ of patients with schizophrenia are obese (BMI $\geq 30$ ), and is a significant contributor to increased CVD risk. [1] Patients with schizophrenia have double the risk of developing obesity than the general population.[5]

The causes of weight gain are complex and multifactorial. Identified genetic, environmental, and disease-specific factors contribute to increased susceptibility.[6] These include high caloric diets combined with a sedentary lifestyle, stigma and discrimination due to mental illness, social isolation, and poor psychotic symptom management.[7] The introduction of second-generation antipsychotics (SGA) such as clozapine, olanzapine, and quetiapine in the 1990s has highlighted the significant impact of metabolic adverse effects (including weight gain) associated with antipsychotic treatment.[8-10] A well-defined hierarchy of weight gain risk associated with both first-generation antipsychotic (FGA) and SGA agents has been established in the literature. However, this is often limited to populations with chronic illness; with young and antipsychotic-naïve patients gaining 3-4fold more weight irrespective of the antipsychotic initiated.[11]

Obesity, type 2 diabetes mellitus, dyslipidaemia, and metabolic syndrome are associated with an increased risk of cardiovascular events.[12] Obesity also affects other lifestyle behaviours, such as increasing social withdrawal[13] and sedentary behaviour[14], both of which are themselves risk factors for worsening cardiometabolic health[15]. Alongside cardiovascular risk, obesity is a modifiable risk factor for other non-communicable diseases which disproportionately reduce life expectancy in people with severe mental illness including multiple types of cancer, liver disease, and respiratory illnesses[16]. Furthermore, if obesity is not appropriately addressed it can negatively influence the patient's view of treatment and reduce medication adherence leading to a deterioration in psychosocial function, an increase in hospital readmissions, and reduced quality of life. $[17,18]$

Additionally, evidence from the general population has provided compelling evidence for casual links for obesity with depression, inflammation, cognitive dysfunction, and neural atrophy[19-21] - all of which are often observed but untreated in patients with schizophrenia despite been associated with worse prognosis and higher burden of illness[22-24]. Importantly, cognitive deficits represent a core symptom domain for schizophrenia with the possibility that the well-recognized metabolic adverse effects of antipsychotics could contribute to cognitive impairments over the course of treatment[25]. Given all of the above, it is clear that the heightened rates of obesity which arise in those taking antipsychotic medications cannot be accepted as a necessary part of treatment and must be addressed in order to improve both physical and functional outcomes of psychotic disorders.

This situation has created challenges for clinicians trying to balance antipsychotic-associated weight gain (AAWG) whilst still ensuring effective treatment of schizophrenia with minimal extra-pyramidal side effects (EPS). We aimed to review the mechanisms for weight gain in schizophrenia and strategies to manage AAWG with an emphasis on maintaining treatment effectiveness in order to guide clinical practice and identify current gaps in research. 


\subsection{Methods}

In this narrative review we examined relevant publications on the mechanisms responsible for inducing obesity in patients with schizophrenia who are taking antipsychotics. We explored the three common therapeutic options employed by clinicians for dealing with this issue: 1) lifestyle intervention and advice; 2 ) switching to another antipsychotic with a reduced propensity to induce metabolic adverse effects; or 3) augmentation with another medication. Other interventions such as bariatric surgery and smoking cessation were beyond the scope of the review. We concentrated on recent studies describing the efficacy and safety of the therapeutic strategy and the its impact on mental health outcomes. We followed the Joanna Briggs Institute (JBI) guidelines for narrative reviews.[26] We searched PubMed and Google Scholar (advanced search) databases from database inception until 29 April 2019 with papers restricted to English. Search terms included (antipsychotic* OR neuroleptic*) AND ("weight gain" OR obesity OR "body mass index" OR "waist circumference").

\subsection{Mechanisms of antipsychotic-induced weight gain}

Obesity is a result of an caloric imbalance where energy intake greatly outweighs energy expenditure, resulting in excessive fat accumulation. [27] Energy homeostasis is a complex interplay of peripheral and central signals, integrated by the hypothalamus and caudal brainstem.[28] Antipsychotics appear to influence and interfere with aspects of this homeostatic control, through the mechanisms described below, resulting in hyperphagia, hyperglycaemia, and reduced energy expenditure.[29]

\subsection{Hormones and peptides}

Central control of satiety and appetite largely occurs in the arcuate nucleus (ARC) of the hypothalamus.[28] The ARC contains an abundance of orexigenic, neuropeptide Y (NPY) and agoutirelated peptide (AgRP), and anorexigenic, pro-opiomelanocortin (POMC) and cocaine- and amphetamine-regulated transcript (CART), neurons that are influenced directly or indirectly by peripheral signals of satiety.[30]

Peripheral hormones such as glucagon-like peptide 1 (GLP-1) and leptin elicit anorexigenic effects. $[28,29,31]$ Changes in circulating levels of these hormones have been observed in patients experiencing AAWG. By reducing GLP-1 secretion, SGAs such as olanzapine, clozapine, and quetiapine impair glucose homeostasis and increase diabetogenic risk in mice.[32,33] Additionally, reduction in GLP-1 alters gustation thereby impairing sweet-taste sensitivity.[34] This is consistent with findings showing olanzapine and clozapine induce cravings for higher-caloric carbohydrate foods. $[33,35]$

Circulating leptin levels increase in parallel with increases in adiposity.[36] Leptin receptors are present throughout the ARC and ventral tegmental area, allowing leptin to mediate its anorexigenic effects through multiple neuronal pathways.[28,37] High levels of leptin are observed in obese patients with schizophrenia suggesting a resistance to endogenous leptin similar to that of obese patients in the general population.[38] This indicates hyperleptinemia is resultant of AAWG rather than a pathophysiological cause.[38,39] Ghrelin is an orexigenic hormone that elicits a response opposite to that of leptin.[36] It plays a large role within satiety homeostasis but conflicting results have been observed with regards to AAWG. [40-43] 
Insulin in the periphery represents an anabolic hormone, while in the central nervous system it has opposing catabolic and anorexigenic effects; through modulation of the reward system and homeostatic signals in the hypothalamus insulin reduces feeding, impacts food preferences, and lowers glucose production at the liver.[44] In turn, weight gain and adiposity associated with antipsychotic medications can indirectly result in insulin resistance. Moreover, in rodents, antipsychotics can directly, and acutely inhibit whole body insulin action[45,46], as well as central insulin action, leading to disruptions glucose and feeding homeostasis $[47,48]$.

Melatonin, a hormone largely secreted by the pineal gland, is involved in various physiological processes including circadian rhythm, immune modulation, and energy metabolism. [49] Olanzapinetreated subjects demonstrate an increase in weight and visceral adiposity with a corresponding decrease in nocturnal circulating melatonin.[50] Daily supplementation of melatonin restores circulating levels and reduces secondary increases in weight and adiposity.[50,51] Further, seasonal changes in leptin sensitivity are linked to melatonin's regulation of the circadian rhythm.[36]

The role of hormones and peptides is summarised in Table 1.

[Table 1 here]

\subsection{Neurotransmission}

SGAs exhibit mixed receptor antagonism with varying effects on dopaminergic, serotoninergic, histaminergic, cholinergic, and adrenergic receptors.[10] This variation is considered a mechanism by which SGAs induce fewer extrapyramidal and prolactin-related adverse effects than FGAs but increase weight and alter metabolic parameters. $[6,10]$ Literature largely revolves around the effects of SGAs on central neurotransmission, with the role of peripheral receptors less clear and understood.[36]

The importance of the dopaminergic system as a mechanism of weight gain was originally neglected in favour of other targets but associations between dopamine and feeding behaviour have become apparent.[6,52,53] Dopaminergic neurons located in the mesolimbic pathway, from the ventral tegmental area to the striatum, regulate reward-associated behaviour and have a significant influence on appetite.[52,53] D2 receptor deficiency in this pathway increases reward-seeking behaviour e.g. increased food intake and appetite in obese individuals. [52,54]

Antagonism of the serotonin receptors, particularly the 5-HT2A and 5-HT2C receptor subtypes, is a characteristic of many SGAs and is widely implicated as a pathway involved in weight gain.[36] Serotonin is a key component of the homeostatic control of satiety and appetite, with expression of the $5-\mathrm{HT} 2 \mathrm{C}$ receptor on POMC and NPY neurons in the ARC.[36,55] Mice treated with olanzapine have shown greater appetite and corresponding weight gain but locaserin - a 5-HT2C agonist diminished this.[56] This suggests that antagonism of 5-HT2C induces weight gain.[56] Further substantiating the significance of the $5-\mathrm{HT} 2 \mathrm{C}$ receptor in terms of weight gain, olanzapine and clozapine are inverse agonists and induce more weight gain than ziprasidone and aripiprazole, which are partial agonists. $[6,53,57]$ Limited data is available concerning the involvement of the 5-HT2A receptor. However, a study in fifteen antipsychotic-naïve patients experiencing their first-episode of schizophrenia has shown a possible link.[58] In this study neocortical binding of 5-HT2A by quetiapine positively correlated with an increase in BMI.[58]

Additionally, histamine $1(\mathrm{H} 1)$ receptors further coordinate energy homeostasis.[29] Stimulation of $\mathrm{H} 1$ receptors result in anorexigenic actions. $[29,36]$ However mice administered with clozapine and 
olanzapine, potent $\mathrm{H} 1$ receptor antagonists, demonstrate greater activation of hypothalamic AMPrelated kinase (AMPK), which is associated with appetite stimulation.[59,60] Ziprasidone, haloperidol and aripiprazole - antipsychotics less likely to induce weight gain - did not increase AMPK activity.[59] Additionally, leptin's anorexigenic actions are partly mediated by this histaminergic pathway and increased AMPK activity disrupts and nullifies these actions.[29]

The role of neuroreceptors is summarised in Table 2.

[Table 2 here]

\subsection{Pharmacogenetics}

An array of genes and single nucleotide polymorphisms (SNP) are potential contributors to AAWG. The HTR2C gene, which encodes the 5-HT2C receptor, is the most researched factor with the SNP rs3813929 the most consistently reported.[61,62] The T allele has increased transcriptional activity, resulting in higher numbers of $5-\mathrm{HT} 2 \mathrm{C}$ receptors, which appears to protect against AAWG in contrast to the more frequent wildtype $C$ allele.[61] Among people on clozapine, the SNP rs381328 in HTR2C with a $T$ allele was associated with a lower BMI compared to the $C$ allele.[63] Other treatmentrelated genes with robust association with AAWG include DRD2 and ADRA2A, which are the precursors for the dopamine D2 receptor and alpha 2A receptor, respectively.[61]

The genes associated with obesity in the general population are also implicated in AAWG. The GNB3 and MC4R genes have been extensively covered in gene-wide association studies and significant links with obesity reported.[61] This link appears to work via impacts on the endogenous hormone and neuronal systems regulating energy homeostasis.[61] Other genes like FTO, LEPR, BDNF, INSIG2, and SNAP25 are also associated with obesity by similarly affecting energy homeostasis.[61,62]

Table 3 summarises frequently identified genes, which contribute to AAWG.

[Table 3 here]

\subsection{Gut microbiome}

More recently, the microbiome-gut-brain axis has been explored as a possible mechanism for weight gain.[53] The gut microbiome interacts directly and indirectly with the central nervous system (CNS) through interactions on the gut surface and the production of neurotransmitters and short-chained fatty acids.[64] It is postulated that this influences the pathophysiology of neuropsychiatric conditions like schizophrenia but, additionally, is implicated as a contributing factor for obesity in patients treated with SGAs.[64]

Mice administered either olanzapine or risperidone demonstrate changes in the composition of the gut microbiota, with increases in the bacterial phylum Firmicutes and decreases in Proteobacteria, Actinobacteria, and particularly Bacteroidetes. The above changes are associated with an increase in body fat. $[65,66]$ These preliminary findings were further supported in a study which attenuated weight gain in olanzapine-treated mice through the co-administration of antibiotics to prevent these microbiota changes.[67] The increase in Firmicutes and decrease in Bacteroidetes following SGA use has been replicated in a small study of 28 male children and adolescents taking regular risperidone compared to controls.[68] Overall, the effects of SGAs on the gut microbiome and the corresponding changes in weight are poorly understood and further research in humans is required and is ongoing. 


\subsection{Treatment for antipsychotic-associated weight gain}

Clinician's strategies to ameliorate AAWG are vital to limit further CVD morbidity and mortality. With an array of pharmacological and non-pharmacological options available the challenge is to employ an effective and feasible approach.

\subsection{Lifestyle interventions}

Reductions in rigorous physical activity and a corresponding increase in sedentary behaviour within the general population is a general trend.[69] Patients with schizophrenia have high levels of sedentary behaviour (an average of 9-10 hours per day), and less physical activity and poorer fitness than the general population.[70,71] Furthermore, individuals with schizophrenia have substantially higher calorie intake than the general population[72] including higher daily intakes of obesogenic foods containing refined carbohydrates and saturated fats.[73] Interventions aimed at optimising exercise and diet appear to be beneficial in attenuating and preventing AAWG but are limited by poor adherence in many patients.

Physical activity interventions are heterogenous in nature with variations in the type and intensity of exercise.[74,75] Significantly increased physical fitness and improved cardiometabolic parameters following exercise is observed in some patients with schizophrenia.[74,75] A recent meta-review reported a significant reduction in body weight (standardised mean difference $=-0.96$ ) with a large effect size after exercise initiation. [76] Further, moderate-to-vigorous exercise has shown a positive effect on psychiatric symptoms and functioning.[74,77] However, the effects of exercise are inconsistent; other studies show no difference in weight, BMI, and psychiatric symptoms compared to usual care. $[78,79]$ Nutritional and dietary interventions have moderate effects on reducing body weight, BMI and waist circumference, and improving blood glucose levels. $[76,80]$ The best results were from interventions led by dieticians.[80]

Exercise and nutrition interventions are frequently used together with other non-pharmacological interventions like cognitive-behavioural therapy (CBT). CBT has shown moderate weight-reducing effects but better results and adherence is observed when $C B T$ is provided alongside structured diet and exercise interventions.[80,81] A high attrition rate is frequently observed in these studies (most following a per protocol analysis), particularly in those involving physical activity. [74,82] Barriers to uptake of these strategies include negative symptoms of schizophrenia, somnolence (possibly induced by treatment), and a lack of supervision and support.[82] This is echoed throughout studies which show individualised interventions outperform group-based interventions but the former are more resource-intensive and initial cost-effectiveness analyses are not promising. [76,78,82] The principles of evidence-based lifestyle interventions, such as the Diabetes Prevention Program, are recommended when designing lifestyle interventions which are effective and engaging for individuals with schizophrenia and other mental illness [4]. Furthermore, using lifestyle interventions from the initiation of antipsychotic treatment - as a preventative strategy - may confer greater benefits for reducing the onset of obesity in patients with schizophrenia [4].

\subsection{Switching antipsychotics}

Switching antipsychotics is a common approach considered for AAWG. SGAs have different weight gain properties and a hierarchy of weight gain potential has been widely reported (Table 4).[6,57,83] 
Patients experiencing AAWG after treatment with high risk of weight gain medications like olanzapine are often switched to SGAs such as aripiprazole, ziprasidone, or amisulpride.[84]

Aripiprazole has a unique mechanism compared to other antipsychotics with partial D2 and 5-HT1A receptor agonism and antagonism of 5-HT2A receptors. [6] A reduced affinity to $\mathrm{H} 1$ and 5-HT2C receptors contributes to the lower risk of weight gain.[85] A multi-site randomised trial including 311 , predominantly male, outpatients switched from other antipsychotics (mostly olanzapine or risperidone) to $30 \mathrm{mg}$ aripiprazole daily reported a mean weight loss of $1.3-1.7 \mathrm{~kg}$ (depending on how quickly antipsychotics were switched) after eight weeks.[86] The study was open-label with an overall discontinuation rate of $28 \%$, largely due to adverse effects (7\%), worsening of schizophrenia (9\%), and withdrawal of consent (6\%).[86]

A more recent 24-week multi-site, randomised study included 215 patients at risk of CVD who had previously been taking olanzapine, risperidone, or quetiapine.[87] Following a four-week crosstitration to aripiprazole (mean dose of $16.9 \mathrm{mg}$ daily), those who switched had a reduction in weight of $2.9 \mathrm{~kg}$ and $\mathrm{BMI}$ of $1.07 \mathrm{~kg} / \mathrm{m} 2$ compared to those who remained on their initial antipsychotic.[87] The study was open-label and included a behavioural intervention aimed at improving diet and exercise.[87] Two in five (43.9\%) switchers and one in four (24.5\%) stayers discontinued their designated antipsychotic before the end of the 24 weeks.[87] One in 12 (8\%) patients dropped out of the aripiprazole arm due to a lack of efficacy. Of the remaining patients there was no difference in treatment efficacy between the groups.[87]

Ziprasidone shows an even lower risk of producing weight gain than aripiprazole.[57,83] It has a relatively high affinity for $\mathrm{H} 1$ and $5-\mathrm{HT} 2 \mathrm{C}$ receptors but its $5-\mathrm{HT} 2 \mathrm{~A} / \mathrm{D} 2$ receptor affinity ratio is much greater than other SGAs. $[6,88]$ A year-long multi-centre open-label study recruited 185 patients experiencing ineffective treatment or adverse effects with risperidone, olanzapine, or FGAs.[89] All were switched to ziprasidone (mean dose of $120 \mathrm{mg}$ daily) and randomised to one of three crosstitration strategies.[89] Switching from either risperidone or olanzapine resulted in a mean reduction in weight of $6.9 \mathrm{~kg}$ and $9.8 \mathrm{~kg}$ at 58 weeks, respectively.[89] There was no change in weight after switching from a FGA.[89] Importantly the reduction in weight gain was incremental over the 12 month period.[89] Like aripiprazole, switching to ziprasidone showed no deterioration in symptoms of schizophrenia in patients continuing therapy for the entire study but this was confounded by a high drop-out rate (61\% of patients at trial conclusion).[89]

A year-long prospective open-label comparison study comprised 52 patients who were switched to either ziprasidone (mean dose $126.5 \mathrm{mg}$ daily) or aripiprazole (mean dose $14.5 \mathrm{mg}$ daily).[90] Significant differences between the ziprasidone and aripiprazole groups for BMI and body weight were only found after 52 weeks of treatment.[90] The ziprasidone group had a mean reduction of $2.3 \mathrm{~kg} / \mathrm{m} 2$ in $\mathrm{BMI}$ and $6.30 \mathrm{~kg}$ in body weight whereas the aripiprazole group had a $0.2 \mathrm{~kg} / \mathrm{m} 2$ and $0.6 \mathrm{~kg}$ reduction at 52 weeks, respectively.[90] Weight loss was greatest for ziprasidone at 52 weeks $(6.30 \mathrm{~kg})$ whereas for aripiprazole weight loss was greatest at 12 weeks $(2.81 \mathrm{~kg})$ suggesting greater long-term incremental weight loss with ziprasidone.[90] These results are limited by a drop-out rate of nearly half (48.1\%) at 12 months, and the open label nature of the study meant patients were able to initiate other drugs such as mood stabilisers.[90] The primary reasons for discontinuation were poor treatment adherence (28\%), patient decision, (24\%) and lack of treatment efficacy (16\%).

Amisulpride is a SGA which demonstrates relatively selective antagonism of D2 and D3 receptors with minimal effects on $\mathrm{H} 1$ and serotonergic receptors.[91] Amisulpride exhibits a moderate potential for weight gain. [6,91] A year-long open-label study of 46 Chinese inpatients switched from SGAs (mostly olanzapine and risperidone) to amisulpride (doses between $600 \mathrm{mg}-1000 \mathrm{mg}$ daily) were 
compared to 46 inpatients who remained on their original SGA.[92] Compared to their baseline weight, patients switched to amisulpride lost $7.8 \mathrm{~kg}$ on average compared to patients who remained on their SGA, who lost $2.6 \mathrm{~kg}$ on average.[92] Within patients switched to amisulpride, 13 did not complete the study, largely due to psychotic symptom exacerbation (69.2\%).[92]

Lurasidone has no significant affinity for $5-\mathrm{HT} 2 \mathrm{C}$ and $\mathrm{H} 1$ receptors and may induce less weight increase.[93] A recent 6-month open-label extension study showed a mean weight reduction of up to $1 \mathrm{~kg}$.[94] Interestingly, this was observed in the subgroup switched from ziprasidone whereas the subgroup switched from risperidone gained $0.7 \mathrm{~kg}$.[94]

Brexipiprazole and cariprazine - newer SGAs with a very similar mechanism of action to aripiprazole - may be a promising alternatives in the future.[95] Reviews suggest cariprazine is associated with fewer incidences of weight gain compared to aripiprazole and brexipiprazole (the agent that appears to cause the most weight gain of the three).[96,97] However, these results are preliminary; there is a paucity of data from randomised controlled trials comparing the agents and reporting on outcomes related to metabolic parameters (including weight gain).

Although switching to ziprasidone or aripiprazole to attenuate AAWG may be effective to reduce weight, clinicians must carefully consider their treatment approach. It is important to select an appropriate switching strategy (e.g. abrupt discontinuation vs cross-tapering) to minimise the risk of relapse and withdrawal symptoms.[98,99] One study compared these strategies when switching to aripiprazole; long-term safety and efficacy outcomes were comparable but abrupt discontinuation induced a higher risk of worsening symptoms within the first two weeks than cross-tapering.[100] In selecting the right strategy, the clinician should consider the severity and duration of illness, presence and quality of surrounding support, and previous experiences with treatment and switching.[98] A robust systematic review and meta-analysis examining the effect of switching on metabolic parameters like weight gain is lacking. Furthermore, confidence in maintaining the efficacy of schizophrenia treatment following switching is hampered by open-label design, varying doses, and high drop-out rates in studies.

As an alternative to switching antipsychotics, dose-lowering strategies have been discussed following evidence of a dose relationship with metabolic adverse effects like weight gain. This has only been observed for olanzapine and clozapine, with other SGAs showing mixed results[101]. However, studies examining this relationship are very limited and the strategy should be avoided until more data is available. Further, greater relapse rates are associated with dose reduction with a significantly higher risk of all-cause and schizophrenia hospital admission and emergency room visits.[102]

[Table 4 here]

\subsection{Augmentation with other medications}

Although several adjunctive pharmacological treatments have been studied, only a few are successful in treating AAWG. Metformin is a first line treatment for type 2 diabetes mellitus in conjunction with lifestyle modification; it decreases intestinal absorption of glucose, increases insulin sensitivity, reduces hepatic gluconeogenesis, and supresses appetite. $[103,104]$ Metformin induces weight loss in diabetic and non-diabetic obese patients with a medium effect size.[76,105] Specific meta-analyses of studies of metformin in patients on clozapine and olanzapine treatment SGAs with the highest liabilities for weight gain - reported mean reductions of $3.12 \mathrm{~kg}$ and $5.02 \mathrm{~kg}$, 
respectively, compared to placebo.[106,107] Interestingly, metformin-associated attenuation of AAWG may be greater in first episode patients compared to chronically ill populations, thereby supporting early intervention approaches.[108]

GLP-1RAs, including exenatide and liraglutide, mimic endogenous GLP-1; enhancing its role in energy and glucose homeostasis.[31] A recent meta-analysis found a mean reduction in body weight of $3.71 \mathrm{~kg}$ with GLP-1RA than controls. [109] Currently both exenatide and liraglutide are subcutaneous injections which presents a potential barrier for treatment; a recent pilot study found fewer than half felt comfortable self-administering the injections.[110] An oral formulation of another recently approved GLP-1RA, semaglutide, is currently being investigated in a phase 3 trial.[111]

Topiramate, an antiepileptic agent, reduces appetite and increases energy expenditure through actions on NPY neurons and leptin mRNA.[112] A recent meta-analysis reported significant reductions in anthropometric measures in patients with schizophrenia, namely a mean weight loss of 3.76kg.[113] However, side effects - including paresthesia and dose-dependent psychomotor slowing and memory disturbance - limit the acceptability of topiramate as a weight-loss augmentation agent. $[113,114]$

Lorcaserin is a $5-\mathrm{HT} 2 \mathrm{C}$ receptor agonist with FDA approval for weight management alongside diet and exercise interventions.[115] Binding of the 5-HT2C receptor in the hypothalamus elicits anorexigenic effects, reducing appetite and food intake.[56,115] Placebo-controlled trials in the general population have showcased encouraging results with the BLOSSOM trial finding significantly more participants achieved greater than $5 \%$ weight loss compared to placebo $(47.2 \%$ on $10 \mathrm{mg}$ twice daily, $40 \%$ on $10 \mathrm{mg}$ daily and $25.0 \%$ on placebo).[116] Case studies reporting weight loss and reduced food cravings in patients experiencing olanzapine-induced weight gain have demonstrated potential benefit for patients with schizophrenia.[117] A randomised-controlled study comparing a combination of metformin and lorcaserin to an active-control of lorcaserin and a control of placebo is currently underway and will provide greater insight for benefit in this population. [118]

Orlistat, a lipase inhibitor, prevents the absorption of dietary fat, allowing it to pass through the body undigested. Benefits within the general population have been reported[119], however a study of 63 patients with schizophrenia treated with olanzapine and clozapine found no difference between orlistat and placebo over 16 weeks regarding weight change, except solely in the male cohort.[76,120] Although discontinuation rates were similar at study conclusion, high drop-out rates have been observed in other studies.[119,120] This is largely due to an unfavourable adverse effect profile including oily spotting on underwear and around the perianal area, increased defecation of oily and fatty stools, faecal urgency/incontinence, and abdominal pain.[121]

Naltrexone (an opioid antagonist) and bupropion (a norepinephrine-dopamine reuptake inhibitor and a nicotinic acetylcholine receptor antagonist) have recently been used in combination to induce weight loss. These agents are believed to synergistically increase activity of hypothalamic POMC neurons thereby reducing appetite.[115] In phase 3 randomised placebo-controlled trials, combinations of sustained-release formulations of naltrexone and bupropion in the general population reduced baseline body weight by $6.4 \% .[122,123]$ Additionally, simultaneous benefit for patients with alcohol, drug and nicotine dependence has been observed.[124] No trials to date examine the combination in patients with schizophrenia.

More recently betahistine has shown promising results. This is a centrally-acting histamine $\mathrm{H} 1$ receptor agonist and $\mathrm{H} 3$ receptor antagonist that reverses olanzapine-induced weight gain in mice.[125] It is relatively well tolerated and is used to treat vestibular disorders.[126] A study in 48 


\subsection{Expert Opinion}

healthy female patients demonstrated that pre-treatment with betahistine as monotherapy for one week prior to coadministration of betahistine and olanzapine for two weeks reduced weight gain compared to placebo and olanzapine (1.24kg gain vs $1.93 \mathrm{~kg}$ gain).[127]

The discovery of new mechanisms for AAWG have seen the emergence of further potential treatments. For instance, the role of melatonin in energy metabolism has already been described with a systematic review exploring the efficacy of melatonin agonists in AAWG.[49] Conflicting results were found in patients depending on the liability of the antipsychotic to induce weight gain.[49] Coadministration of melatonin appears more effective with risperidone and quetiapine agents with an intermediate risk to induce AAWG - compared to olanzapine and clozapine - agents that are high risk.[49] Another option is targeting the microbiome-gut-brain axis.[64] A two-week study in female rats reported that olanzapine-induced weight gain was reduced with the coadministration of a prebiotic galacto-oligosaccharide.[128]

AAWG must be considered in clinical decisions to reduce morbidity and mortality within patients with schizophrenia. Several mechanisms of AAWG are proposed but the phenomenon is still not fully understood. The effects of different neurotransmission systems and genetic factors have the most convincing data. Conflicting results and lack of human data limits the applicability of some evidence involving hormonal systems of energy metabolism and the evolving role of the microbiome-gutbrain axis. Growing knowledge of these mechanisms has been vital in guiding management strategies including new pharmacological treatments and the most appropriate antipsychotic switching regimens. Furthermore, they can form the basis of new antipsychotic agent discovery similarly to that seem with the development of brexipiprazole and cariprazine.

Patients newly diagnosed with schizophrenia and psychosis experience significantly more weight gain and this is reported regardless of the antipsychotic prescribed. AAWG and metabolic abnormalities should be at the forefront of clinician's minds when initiating antipsychotic treatment in newly diagnosed patients. Clinicians should consider an agent that has smaller impact on weight, such as aripiprazole and ziprasidone, with the intention of limiting future morbidity and mortality. Further, prevention plans should be discussed and implemented alongside the commencement of antipsychotic treatment to attenuate weight gain.

When reviewing approaches to ameliorate AAWG in already obese patients, antipsychotic effectiveness is essential to minimise any risk of relapse and hospitalisation. However, management of the associated obesity should not be neglected. Individualised strategies and goals should be implemented considering the patient's severity of weight gain, the history of their condition, and their opinion of treatment. Frequent monitoring of weight and adverse effects (if a pharmacological treatment chosen) should accompany regular symptom control monitoring. This allows clinicians to decide if the approach is effective in reducing weight for the patient and is not having a detrimental effect on schizophrenia treatment.

Although not consistent, lifestyle interventions show some evidence of reducing weight particularly when addressing multiple lifestyle risk factors and making use of specialised health professionals (such as qualified nutrition and physical-activity staff). Such interventions, beyond weight reduction, can also have a positive impact on cardiovascular disease and symptoms of schizophrenia with particularly strong evidence for exercise. Employing these interventions is a challenge, however, with many barriers preventing uptake and long-term effectiveness of the approach. Intensive and 
individual support is often required to promote and maintain adherence to regimens. This is often resource-intensive and preliminary cost effectiveness trials demonstrate poor value for money. Further, lifestyle regimens studied in this population have been substantially heterogenous thereby creating difficulties for clinicians when identifying approaches to employ. Recent guidelines suggest that adhering to principles of evidence-based lifestyle interventions developed in the general population, while using these to protect physical health from the very initiation of treatment (before weight gain has occurred), may provide the optimal approach for preventing AAWG. [4] However, if lifestyle interventions are deemed inappropriate or unsuccessful, pharmacological strategies should then be considered.

With an abundance of data showcasing the propensities of different antipsychotics to induce weight gain, switching antipsychotics is a theoretically sound approach. Evidence suggest patients experience the most weight loss following a switch to aripiprazole, ziprasidone or amisulpride. High discontinuation and drop-out rates, largely due to symptom exacerbation, confound these trials and limit their applicability to the real-world. A lack of homogenous objective outcomes and large focus on treatment efficacy instead of metabolic outcomes in the literature has contributed to a paucity of meta-analysable data. Research in the future should aim to critically appraise current literature through a systematic review and re-enforce the current gaps in knowledge including which agents are most effective and whether the risks of relapse outweigh the benefits in reducing weight.

Additionally, augmentation with other medications has proven effective in ameliorating AAWG. Metformin and GLP-1RAs are the most promising agents, with an abundance of data demonstrating effectiveness and few incidences of side effects. GLP-1RAs are currently limited by a subcutaneous formulation but the recent development of an oral agent could create a larger role for the medication class in the future. Novel developments into the use of lorcaserin and a combination of naltrexone and bupropion have shown great benefit in the general population and preliminary results in patients with schizophrenia have so far supported these previous results. More experimental treatments including betahistine, melatonin agonists, and prebiotics, evolving from new research into mechanisms of AAWG require larger, well-designed long-term randomised controlled data in human populations.

Overall, the importance of improving cardiometabolic health in patients with schizophrenia has been recognised yet neglected for decades. Ameliorating obesity once it has occurred is challenging and often not achieved by clinicians. A standardised strategy for reversing weight gain is unlikely to be able to be recommended. Lifestyle intervention and augmentation with other medications are the most feasible but only showcase modest effects. Switching antipsychotics presents a higher risk of symptom exacerbation in patients in remission and similarly exhibit modest reduction in weight. Preventing AAWG and related complications with carefully considered initiation of antipsychotics is widely accepted and should aim to be the focus of guidelines and treatments in the coming years. 


\author{
Funding \\ DS is supported in part by an NHMRC APP1111136
}

\title{
Declaration of Interests
}

$\mathrm{DS}, \mathrm{WM}, \mathrm{SH}, \mathrm{JF}, \mathrm{EG}$ and $\mathrm{KW}$ have no interests to declare.

BHE has received lecture fees and/or is part of Advisory Boards of Bristol-Myers Squibb, Eli Lilly and Company, Janssen-Cilag, Otsuka Pharma Scandinavia AB, Takeda Pharmaceutical Company and Lundbeck Pharma A/S.

MKH has been on an advisory board for Alkermes.

SK has received speaker's honoraria from Janssen 


\section{References}

1. Correll CU, Solmi M, Veronese N, et al. Prevalence, incidence and mortality from cardiovascular disease in patients with pooled and specific severe mental illness: a largescale meta-analysis of 3,211,768 patients and 113,383,368 controls. World Psychiatry. 2017 Jun;16(2):163-180.

2. Lawrence D, Hancock KJ, Kisely S. The gap in life expectancy from preventable physical illness in psychiatric patients in Western Australia: retrospective analysis of population based registers. BMJ. 2013 May 21;346:f2539.

3. Oakley P, Kisely S, Baxter A, et al. Increased mortality among people with schizophrenia and other non-affective psychotic disorders in the community: A systematic review and metaanalysis. Journal of psychiatric research. $2018 \mathrm{Jul} ; 102: 245-253$.

4. Firth J, Siddiqi N, Koyanagi A, et al. The Lancet Psychiatry Commission: A Blueprint for Protecting Physical Health in People with Mental Illness. The Lancet Psychiatry. 2019;6:675712.

5. De Hert M, Dekker JM, Wood D, et al. Cardiovascular disease and diabetes in people with severe mental illness position statement from the European Psychiatric Association (EPA), supported by the European Association for the Study of Diabetes (EASD) and the European Society of Cardiology (ESC). Eur Psychiatry. 2009 Sep;24(6):412-24.

6. Correll CU, Lencz T, Malhotra AK. Antipsychotic drugs and obesity. Trends Mol Med. 2011 Feb;17(2):97-107.

7. Manu P, Dima L, Shulman M, et al. Weight gain and obesity in schizophrenia: epidemiology, pathobiology, and management. Acta Psychiatr Scand. 2015 Aug;132(2):97-108.

8. McIntyre RS, McCann SM, Kennedy SH. Antipsychotic metabolic effects: weight gain, diabetes mellitus, and lipid abnormalities. Can J Psychiatry. 2001 Apr;46(3):273-81.

9. Falissard B, Mauri M, Shaw K, et al. The METEOR study: frequency of metabolic disorders in patients with schizophrenia. Focus on first and second generation and level of risk of antipsychotic drugs. International clinical psychopharmacology. 2011 Nov;26(6):291-302.

10. Shen WW. A history of antipsychotic drug development. Compr Psychiatry. 1999 NovDec;40(6):407-14.

11. Álvarez-Jiménez M, González-Blanch C, Crespo-Facorro B, et al. Antipsychotic-Induced Weight Gain in Chronic and First-Episode Psychotic Disorders. CNS Drugs. 2008 2008/07/01;22(7):547-562.

12. Leon BM, Maddox TM. Diabetes and cardiovascular disease: Epidemiology, biological mechanisms, treatment recommendations and future research. World J Diabetes. 2015 Oct 10;6(13):1246-58.

13. Wang J, Lloyd-Evans B, Giacco D, et al. Social isolation in mental health: a conceptual and methodological review. Social psychiatry and psychiatric epidemiology. 2017 Dec;52(12):1451-1461.

14. Vancampfort D, Firth J, Schuch FB, et al. Sedentary behavior and physical activity levels in people with schizophrenia, bipolar disorder and major depressive disorder: a global systematic review and meta-analysis. World Psychiatry. 2017 October;16(3):308-315.

15. Wilmot EG, Edwardson CL, Achana FA, et al. Sedentary time in adults and the association with diabetes, cardiovascular disease and death: systematic review and meta-analysis. Diabetologia. 2012;55(11):2895-2905.

16. Iyengar NM, Hudis CA, Dannenberg AJ. Obesity and cancer: local and systemic mechanisms. Annual review of medicine. 2015;66:297-309. 
17. Weiden PJ, Mackell JA, McDonnell DD. Obesity as a risk factor for antipsychotic noncompliance. Schizophr Res. 2004 2004/01/01/;66(1):51-57.

18. Manu P, Khan S, Radhakrishnan R, et al. Body mass index identified as an independent predictor of psychiatric readmission. The Journal of clinical psychiatry. 2014;75(6):e573-7.

19. Hamer M, Batty GD. Association of body mass index and waist-to-hip ratio with brain structure: UK Biobank study. Neurology. 2019;92(6):e594-e600.

20. van den Broek N, Treur JL, Larsen JK, et al. Causal associations between body mass index and mental health: a Mendelian randomisation study. J Epidemiol Community Health. 2018;72(8):708-710.

21. Nguyen JC, Killcross AS, Jenkins TA. Obesity and cognitive decline: role of inflammation and vascular changes. Frontiers in neuroscience. 2014;8:375.

22. Bellack AS. Cognitive rehabilitation for schizophrenia: Is it possible? Is it necessary? [Note]. Schizophrenia Bull. 1992;18(1):43-50.

23. Fraguas D, Diaz-Caneja CM, Rodriguez-Quiroga A, et al. Oxidative Stress and Inflammation in Early Onset First Episode Psychosis: A Systematic Review and Meta-Analysis [Meta-Analysis

Review

Research Support, Non-U.S. Gov't]. International Journal of Neuropsychopharmacology. 201706 01;20(6):435-444.

24. Steullet $\mathrm{P}$, Cabungcal JH, Monin A, et al. Redox dysregulation, neuroinflammation, and NMDA receptor hypofunction: A "central hub" in schizophrenia pathophysiology? [Review]. Schizophr Res. 201601 Sep;176(1):41-51.

25. MacKenzie NE, Kowalchuk C, Agarwal SM, et al. Antipsychotics, Metabolic Adverse Effects, and Cognitive Function in Schizophrenia. Front Psychiatry. 2018;9:622.

26. Peters M, Godfrey C, McInerney P, et al. Chapter 11: Scoping Reviews. In: Aromataris E, Munn Z, editors. Joanna Briggs Institute Reviewer's Manual. Adelaide: The Joanna Briggs Institute; 2017.

27. Hill JO, Wyatt HR, Peters JC. Energy balance and obesity. Circulation. 2012 Jul 3;126(1):12632.

28. Valassi E, Scacchi M, Cavagnini F. Neuroendocrine control of food intake. Nutrition, metabolism, and cardiovascular diseases : NMCD. 2008 Feb;18(2):158-68.

29. Balt SL, Galloway GP, Baggott MJ, et al. Mechanisms and genetics of antipsychoticassociated weight gain. Clinical pharmacology and therapeutics. $2011 \mathrm{Jul} ; 90(1): 179-83$.

30. Benelam B. Satiation, satiety and their effects on eating behaviour. Nutrition Bulletin. 2009;34(2):126-173.

31. Mayfield K, Siskind D, Winckel K, et al. Glucagon-like peptide-1 agonists combating clozapine-associated obesity and diabetes. J Psychopharmacol. 2016 Mar;30(3):227-36.

32. Smith GC, Vickers MH, Cognard E, et al. Clozapine and quetiapine acutely reduce glucagonlike peptide-1 production and increase glucagon release in obese rats: implications for glucose metabolism and food choice behaviour. Schizophr Res. 2009 Nov;115(1):30-40.

33. Smith GC, Vickers MH, Shepherd PR. Olanzapine effects on body composition, food preference, glucose metabolism and insulin sensitivity in the rat. Archives of physiology and biochemistry. 2011 Oct;117(4):241-9.

34. Shin YK, Martin B, Golden E, et al. Modulation of taste sensitivity by GLP-1 signaling. J Neurochem. 2008 Jul;106(1):455-63.

35. Kluge $\mathrm{M}$, Schuld $\mathrm{A}$, Himmerich $\mathrm{H}$, et al. Clozapine and olanzapine are associated with food craving and binge eating: results from a randomized double-blind study. Journal of clinical psychopharmacology. 2007 Dec;27(6):662-6.

36. Coccurello R, Moles A. Potential mechanisms of atypical antipsychotic-induced metabolic derangement: clues for understanding obesity and novel drug design. Pharmacol Ther. 2010 Sep;127(3):210-51. 
37. Opland DM, Leinninger GM, Myers MG, Jr. Modulation of the mesolimbic dopamine system by leptin. Brain Res. 2010 Sep 2;1350:65-70.

38. Potvin S, Zhornitsky S, Stip E. Antipsychotic-induced changes in blood levels of leptin in schizophrenia: a meta-analysis. Can J Psychiatry. 2015 Mar;60(3 Suppl 2):S26-34.

39. Jin H, Meyer JM, Mudaliar S, et al. Impact of atypical antipsychotic therapy on leptin, ghrelin, and adiponectin. Schizophr Res. 2008 Mar;100(1-3):70-85.

40. Firth J, Teasdale SB, Jackson SE, et al. Do reductions in ghrelin contribute towards antipsychotic-induced weight gain? Schizophr Res. 2018.

41. Zhang $\mathrm{Q}, \mathrm{He} \mathrm{M}$, Deng $\mathrm{C}$, et al. Hypothalamic ghrelin signalling mediates olanzapine-induced hyperphagia and weight gain in female rats. Int J Neuropsychopharmacol. 2014 May;17(5):807-18.

42. van der Zwaal EM, Merkestein M, Lam YK, et al. The acute effects of olanzapine on ghrelin secretion, CCK sensitivity, meal size, locomotor activity and body temperature [Original Article]. Int J Obes (Lond). 2012 Feb;36(2):254-61.

43. Goetz RL, Miller BJ. Meta-analysis of ghrelin alterations in schizophrenia: Effects of olanzapine. Schizophr Res. 2018 Dec 7.

44. Vogt MC, Brüning JC. CNS insulin signaling in the control of energy homeostasis and glucose metabolism \&\#x2013; from embryo to old age. Trends in Endocrinology \& Metabolism. 2013;24(2):76-84.

45. Houseknecht KL, Robertson AS, Zavadoski W, et al. Acute effects of atypical antipsychotics on whole-body insulin resistance in rats: implications for adverse metabolic effects. Neuropsychopharmacology : official publication of the American College of Neuropsychopharmacology. 2007 Feb;32(2):289-97.

46. Guenette MD, Giacca A, Hahn M, et al. Atypical antipsychotics and effects of adrenergic and serotonergic receptor binding on insulin secretion in-vivo: An animal model. Schizophr Res. 2013 2013/05/01/;146(1):162-169.

47. Castellani LN, Wilkin J, Abela AR, et al. Effects of acute olanzapine exposure on central insulin-mediated regulation of whole body fuel selection and feeding. Psychoneuroendocrinology. 2018 Dec;98:127-130.

48. Kowalchuk C, Teo C, Wilson V, et al. In male rats, the ability of central insulin to suppress glucose production is impaired by olanzapine, whereas glucose uptake is left intact. J Psychiatry Neurosci. 2017 Nov;42(6):424-431.

49. Wang HR, Woo YS, Bahk WM. The role of melatonin and melatonin agonists in counteracting antipsychotic-induced metabolic side effects: a systematic review. International clinical psychopharmacology. 2016 Nov;31(6):301-6.

50. Raskind MA, Burke BL, Crites NJ, et al. Olanzapine-induced weight gain and increased visceral adiposity is blocked by melatonin replacement therapy in rats. Neuropsychopharmacology : official publication of the American College of Neuropsychopharmacology. 2007 Feb;32(2):284-8.

51. Terron MP, Delgado-Adamez J, Pariente JA, et al. Melatonin reduces body weight gain and increases nocturnal activity in male Wistar rats. Physiol Behav. 2013 Jun 13;118:8-13.

52. van Galen KA, Ter Horst KW, Booij J, et al. The role of central dopamine and serotonin in human obesity: lessons learned from molecular neuroimaging studies. Metabolism. 2018 Aug;85:325-339.

53. Singh R, Bansal Y, Medhi B, et al. Antipsychotics-induced metabolic alterations: Recounting the mechanistic insights, therapeutic targets and pharmacological alternatives. Eur J Pharmacol. 2019 Feb 5;844:231-240.

54. Nielsen MO, Rostrup E, Wulff S, et al. Striatal Reward Activity and Antipsychotic-Associated Weight Change in Patients With Schizophrenia Undergoing Initial Treatment. JAMA psychiatry. 2016 Feb;73(2):121-8. 
55. Blundell JE, Halford JCG. Serotonin and Appetite Regulation [journal article]. CNS Drugs. 1998 June 01;9(6):473-495.

56. Lord CC, Wyler SC, Wan R, et al. The atypical antipsychotic olanzapine causes weight gain by targeting serotonin receptor 2C. The Journal of clinical investigation. $2017 \mathrm{Sep}$ 1;127(9):3402-3406.

57. Rummel-Kluge C, Komossa K, Schwarz S, et al. Head-to-head comparisons of metabolic side effects of second generation antipsychotics in the treatment of schizophrenia: a systematic review and meta-analysis. Schizophr Res. 2010 Nov;123(2-3):225-33.

58. Rasmussen $\mathrm{H}$, Ebdrup BH, Oranje B, et al. Neocortical serotonin2A receptor binding predicts quetiapine associated weight gain in antipsychotic-naive first-episode schizophrenia patients. Int J Neuropsychopharmacol. 2014 Nov;17(11):1729-36.

59. Kim SF, Huang AS, Snowman AM, et al. From the Cover: Antipsychotic drug-induced weight gain mediated by histamine $\mathrm{H} 1$ receptor-linked activation of hypothalamic AMP-kinase. Proc Natl Acad Sci U S A. 2007 Feb 27;104(9):3456-9.

60. He $M$, Zhang $Q$, Deng $C$, et al. Hypothalamic histamine $H 1$ receptor-AMPK signaling timedependently mediates olanzapine-induced hyperphagia and weight gain in female rats. Psychoneuroendocrinology. 2014 Apr;42:153-64.

61. Malhotra AK, Robinson DG, Lencz T, et al. Pharmacogenetic Associations of Antipsychotic Drug-Related Weight Gain: A Systematic Review and Meta-analysis. Schizophrenia Bull. 2016 Nov;42(6):1418-1437.

62. Zhang JP, Malhotra AK. Recent Progress in Pharmacogenomics of Antipsychotic Drug Response [journal article]. Curr Psychiatry Rep. 2018 Mar 27;20(4):24.

63. Suetani RJ, Siskind D, Reichhold H, et al. Genetic variants impacting metabolic outcomes among people on clozapine: a systematic review and meta-analysis. Psychopharmacology. 2017 Oct;234(20):2989-3008.

64. Kanji S, Fonseka TM, Marshe VS, et al. The microbiome-gut-brain axis: implications for schizophrenia and antipsychotic induced weight gain [journal article]. Eur Arch Psychiatry Clin Neurosci. 2018 Feb;268(1):3-15.

65. Davey KJ, O'Mahony SM, Schellekens H, et al. Gender-dependent consequences of chronic olanzapine in the rat: effects on body weight, inflammatory, metabolic and microbiota parameters. Psychopharmacology. 2012 May;221(1):155-69.

66. Bahra SM, Weidemann BJ, Castro AN, et al. Risperidone-induced weight gain is mediated through shifts in the gut microbiome and suppression of energy expenditure. EBioMedicine. 2015 Nov;2(11):1725-34.

67. Davey KJ, Cotter PD, O'Sullivan O, et al. Antipsychotics and the gut microbiome: olanzapineinduced metabolic dysfunction is attenuated by antibiotic administration in the rat. Translational psychiatry. 2013 Oct 1;3:e309.

68. Bahr SM, Tyler BC, Wooldridge N, et al. Use of the second-generation antipsychotic, risperidone, and secondary weight gain are associated with an altered gut microbiota in children. Translational psychiatry. 2015 Oct 6;5:e652.

69. Hallal PC, Andersen LB, Bull FC, et al. Global physical activity levels: surveillance progress, pitfalls, and prospects. The Lancet. 2012 2012/07/21/;380(9838):247-257.

70. Andersen E, Holmen TL, Egeland J, et al. Physical activity pattern and cardiorespiratory fitness in individuals with schizophrenia compared with a population-based sample. Schizophr Res. 2018 2018/11/01/;201:98-104.

71. Stubbs B, Firth J, Berry A, et al. How much physical activity do people with schizophrenia engage in? A systematic review, comparative meta-analysis and meta-regression. Schizophr Res. 2016 Oct;176(2-3):431-440.

72. Teasdale SB, Ward PB, Samaras K, et al. Dietary intake of people with severe mental illness: systematic review and meta-analysis. The British Journal of Psychiatry. 2019:1-9. 
73. Firth J, Stubbs B, Teasdale SB, et al. Diet as a hot topic in psychiatry: a population-scale study of nutritional intake and inflammatory potential in severe mental illness. World Psychiatry. 2018;17(3):365-367.

74. Firth J, Cotter J, Elliott R, et al. A systematic review and meta-analysis of exercise interventions in schizophrenia patients. Psychological medicine. 2015 May;45(7):1343-61.

75. Pearsall R, Smith DJ, Pelosi A, et al. Exercise therapy in adults with serious mental illness: a systematic review and meta-analysis. BMC psychiatry. 2014 Apr 21;14:117.

76. Vancampfort D, Firth J, Correll CU, et al. The impact of pharmacological and nonpharmacological interventions to improve physical health outcomes in people with schizophrenia: a meta-review of meta-analyses of randomized controlled trials. World Psychiatry. 2019 Feb;18(1):53-66.

77. Stubbs $B$, Vancampfort $D$, Hallgren $M$, et al. EPA guidance on physical activity as a treatment for severe mental illness: a meta-review of the evidence and Position Statement from the European Psychiatric Association (EPA), supported by the International Organization of Physical Therapists in Mental Health (IOPTMH). European Psychiatry. 2018 Oct;54:124-144.

78. Holt RIG, Gossage-Worrall R, Hind D, et al. Structured lifestyle education for people with schizophrenia, schizoaffective disorder and first-episode psychosis (STEPWISE): randomised controlled trial. Br J Psychiatry. 2019 Feb;214(2):63-73.

79. Speyer $\mathrm{H}$, Christian Brix Norgaard H, Birk M, et al. The CHANGE trial: no superiority of lifestyle coaching plus care coordination plus treatment as usual compared to treatment as usual alone in reducing risk of cardiovascular disease in adults with schizophrenia spectrum disorders and abdominal obesity. World Psychiatry. 2016 Jun;15(2):155-65.

80. Teasdale SB, Ward PB, Rosenbaum S, et al. Solving a weighty problem: systematic review and meta-analysis of nutrition interventions in severe mental illness. Br J Psychiatry. 2017 Feb;210(2):110-118.

81. Caemmerer J, Correll CU, Maayan L. Acute and maintenance effects of non-pharmacologic interventions for antipsychotic associated weight gain and metabolic abnormalities: A metaanalytic comparison of randomized controlled trials. Schizophr Res. 2012 2012/09/01/;140(1):159-168.

82. Firth J, Rosenbaum S, Stubbs B, et al. Motivating factors and barriers towards exercise in severe mental illness: a systematic review and meta-analysis. Psychological medicine. 2016;46(14):2869-2881.

83. Leucht S, Cipriani A, Spineli L, et al. Comparative efficacy and tolerability of 15 antipsychotic drugs in schizophrenia: a multiple-treatments meta-analysis. Lancet. $2013 \mathrm{Sep}$ 14;382(9896):951-62.

84. Hasnain M, Vieweg WV. Weight considerations in psychotropic drug prescribing and switching. Postgrad Med. 2013 Sep;125(5):117-29.

85. Di Sciascio G, Riva MA. Aripiprazole: from pharmacological profile to clinical use. Neuropsychiatr Dis Treat. 2015;11:2635-47.

86. Casey DE, Carson WH, Saha AR, et al. Switching patients to aripiprazole from other antipsychotic agents: a multicenter randomized study. Psychopharmacology. 2003 Apr;166(4):391-9.

87. Stroup TS, McEvoy JP, Ring KD, et al. A randomized trial examining the effectiveness of switching from olanzapine, quetiapine, or risperidone to aripiprazole to reduce metabolic risk: comparison of antipsychotics for metabolic problems (CAMP). The American journal of psychiatry. 2011 Sep;168(9):947-56.

88. Stimmel GL, Gutierrez MA, Lee V. Ziprasidone: an atypical antipsychotic drug for the treatment of schizophrenia. Clin Ther. 2002 Jan;24(1):21-37.

89. Weiden PJ, Newcomer JW, Loebel AD, et al. Long-term changes in weight and plasma lipids during maintenance treatment with ziprasidone. Neuropsychopharmacology : official publication of the American College of Neuropsychopharmacology. 2008 Apr;33(5):985-94. 
90. Chen Y, Bobo WV, Watts K, et al. Comparative effectiveness of switching antipsychotic drug treatment to aripiprazole or ziprasidone for improving metabolic profile and atherogenic dyslipidemia: a 12-month, prospective, open-label study. J Psychopharmacol. 2012 Sep;26(9):1201-10.

91. Moller HJ. Amisulpride: limbic specificity and the mechanism of antipsychotic atypicality. Prog Neuropsychopharmacol Biol Psychiatry. 2003 Oct;27(7):1101-11.

92. Lin CC, Bai YM, Wang YC, et al. Improved body weight and metabolic outcomes in overweight or obese psychiatric patients switched to amisulpride from other atypical antipsychotics. Journal of clinical psychopharmacology. 2009 Dec;29(6):529-36.

93. McEvoy JP, Citrome L, Hernandez D, et al. Effectiveness of lurasidone in patients with schizophrenia or schizoaffective disorder switched from other antipsychotics: a randomized, 6-week, open-label study. The Journal of clinical psychiatry. 2013 Feb;74(2):170-9.

94. Citrome L, Weiden PJ, McEvoy JP, et al. Effectiveness of lurasidone in schizophrenia or schizoaffective patients switched from other antipsychotics: a 6-month, open-label, extension study. CNS spectrums. 2014 Aug;19(4):330-9.

95. Hope J, Castle D, Keks NA. Brexpiprazole: a new leaf on the partial dopamine agonist branch. Australas Psychiatry. 2018 Feb;26(1):92-94.

96. Citrome L. The ABC's of dopamine receptor partial agonists - aripiprazole, brexpiprazole and cariprazine: the 15-min challenge to sort these agents out. International Journal of Clinical Practice. 2015;69(11):1211-1220.

97. Frankel JS, Schwartz TL. Brexpiprazole and cariprazine: distinguishing two new atypical antipsychotics from the original dopamine stabilizer aripiprazole. Therapeutic Advances in Psychopharmacology. 2017;7(1):29-41.

98. Burns T, Chabannes JP, Demyttenaere K. Switching antipsychotic medications: general recommendations and switching to amisulpride. Curr Med Res Opin. 2002 2002/01/01;18(4):201-8.

99. Weber $M$, Gutierrez AM, Mohammadi $M$. The risks and benefits of switching antipsychotics: a case study approach. Perspect Psychiatr Care. 2009 Jan;45(1):54-61.

100. Pae CU, Serretti A, Chiesa A, et al. Immediate versus gradual suspension of previous treatments during switch to aripiprazole: results of a randomized, open label study. European neuropsychopharmacology : the journal of the European College of Neuropsychopharmacology. 2009 Aug;19(8):562-70.

101. Simon V, van Winkel R, De Hert M. Are weight gain and metabolic side effects of atypical antipsychotics dose dependent? A literature review. The Journal of clinical psychiatry. 2009 2009/07//;70(7):1041-1050.

102. Caroff SN, Mu F, Ayyagari R, et al. Hospital utilization rates following antipsychotic dose reductions: implications for tardive dyskinesia. BMC psychiatry. 2018 2018/09/24;18(1):306.

103. Lee A, Morley JE. Metformin decreases food consumption and induces weight loss in subjects with obesity with type II non-insulin-dependent diabetes. Obes Res. 1998 Jan;6(1):47-53.

104. Pernicova I, Korbonits M. Metformin-mode of action and clinical implications for diabetes and cancer [Review Article]. Nature Reviews Endocrinology. 2014 01/07/online;10:143.

105. Seifarth C, Schehler B, Schneider HJ. Effectiveness of metformin on weight loss in nondiabetic individuals with obesity. Exp Clin Endocrinol Diabetes. 2013 Jan;121(1):27-31.

106. Siskind DJ, Leung J, Russell AW, et al. Metformin for Clozapine Associated Obesity: A Systematic Review and Meta-Analysis. PloS one. 2016;11(6):e0156208.

107. Praharaj SK, Jana AK, Goyal N, et al. Metformin for olanzapine-induced weight gain: a systematic review and meta-analysis. Br J Clin Pharmacol. 2011 Mar;71(3):377-82.

108. Maayan L, Vakhrusheva J, Correll CU. Effectiveness of medications used to attenuate antipsychotic-related weight gain and metabolic abnormalities: a systematic review and 
meta-analysis. Neuropsychopharmacology : official publication of the American College of Neuropsychopharmacology. 2010 Jun;35(7):1520-1530.

109. Siskind D, Hahn M, Correll CU, et al. Glucagon-like peptide-1 receptor agonists for antipsychotic-associated cardio-metabolic risk factors: A systematic review and individual participant data meta-analysis. Diabetes, obesity \& metabolism. 2019 Feb;21(2):293-302.

110. Siskind DJ, Russell AW, Gamble C, et al. Treatment of clozapine-associated obesity and diabetes with exenatide in adults with schizophrenia: A randomized controlled trial (CODEX). Diabetes, obesity \& metabolism. 2018 Apr;20(4):1050-1055.

111. Dhillon S. Semaglutide: First Global Approval [journal article]. Drugs. 2018 Feb;78(2):275284.

112. Rege S. Antipsychotic induced weight gain in schizophrenia:mechanisms and management. Aust N Z J Psychiatry. 2008 May;42(5):369-81.

113. Goh KK, Chen CH, Lu ML. Topiramate mitigates weight gain in antipsychotic-treated patients with schizophrenia: meta-analysis of randomised controlled trials. Int J Psychiatry Clin Pract. 2019 Mar;23(1):14-32.

114. Loring DW, Williamson DJ, Meador KJ, et al. Topiramate dose effects on cognition: a randomized double-blind study. Neurology. 2011 Jan 11;76(2):131-7.

115. Hocking S, Dear A, Cowley MA. Current and emerging pharmacotherapies for obesity in Australia. Obes Res Clin Pract. 2017 Sep - Oct;11(5):501-521.

116. Fidler MC, Group ftBCT, Sanchez M, et al. A One-Year Randomized Trial of Lorcaserin for Weight Loss in Obese and Overweight Adults: The BLOSSOM Trial. The Journal of Clinical Endocrinology \& Metabolism. 2011;96(10):3067-3077.

117. Nguyen C, Suzuki A, Bera K. Use of Lorcaserin, A 5HT2C Agonist, In the Management of Olanzapine Induced Weight Gain [Case Report]. Journal of Metabolic Syndrome. 2015;4(4).

118. ClinicalTrials.gov. Identifier: NCT02796144: MEtformin and Lorcaserin for WeighT Loss in Schizophrenia (MELT) Bethesda, Maryland: U.S. National Library of Medicine; 2016 [cited 2019 07/07/19]. Available from:

https://clinicaltrials.gov/ct2/show/NCT02796144?term=lorcaserin\&cond=Schizophrenia\&ra $\underline{n k=1}$

119. Torgerson JS, Hauptman J, Boldrin MN, et al. XENical in the Prevention of Diabetes in Obese Subjects (XENDOS) Study. A randomized study of orlistat as an adjunct to lifestyle changes for the prevention of type 2 diabetes in obese patients. 2004;27(1):155-161.

120. Joffe $G$, Takala $P$, Tchoukhine $E$, et al. Orlistat in clozapine- or olanzapine-treated patients with overweight or obesity: a 16-week randomized, double-blind, placebo-controlled trial. The Journal of clinical psychiatry. 2008 May;69(5):706-11.

121. Drew BS, Dixon AF, Dixon JB. Obesity management: update on orlistat. Vasc Health Risk Manag. 2007;3(6):817-821.

122. Greenway FL, Fujioka K, Plodkowski RA, et al. Effect of naltrexone plus bupropion on weight loss in overweight and obese adults (COR-I): a multicentre, randomised, double-blind, placebo-controlled, phase 3 trial. The Lancet. 2010 2010/08/21/;376(9741):595-605.

123. Apovian CM, Aronne L, Rubino D, et al. A randomized, phase 3 trial of naltrexone SR/bupropion SR on weight and obesity-related risk factors (COR-II). Obesity. 2013;21(5):935-943.

124. Tek $\mathrm{C}$. Naltrexone $\mathrm{HCl} /$ bupropion $\mathrm{HCl}$ for chronic weight management in obese adults: patient selection and perspectives. Patient Prefer Adherence. 2016;10:751-759.

125. Lian J, Huang XF, Pai N, et al. Betahistine ameliorates olanzapine-induced weight gain through modulation of histaminergic, NPY and AMPK pathways. Psychoneuroendocrinology. 2014 Oct; 48:77-86.

126. Lian J, Huang XF, Pai N, et al. Ameliorating antipsychotic-induced weight gain by betahistine: Mechanisms and clinical implications. Pharmacol Res. 2016 Apr;106:51-63. 
127. Barak N, Beck Y, Albeck JH. Betahistine decreases olanzapine-induced weight gain and somnolence in humans. J Psychopharmacol. 2016 Mar;30(3):237-41.

128. Kao AC, Spitzer S, Anthony DC, et al. Prebiotic attenuation of olanzapine-induced weight gain in rats: analysis of central and peripheral biomarkers and gut microbiota. Translational psychiatry. 2018 Mar 15;8(1):66. 
Table 1: Summary of hormone/peptides role in energy homeostasis and the impact of antipsychotics

\begin{tabular}{|c|c|c|}
\hline $\begin{array}{l}\text { Hormone or } \\
\text { Peptide }\end{array}$ & $\begin{array}{l}\text { Role in normal energy metabolism } \\
\text { and homeostasis }\end{array}$ & $\begin{array}{l}\text { Antipsychotics impact } \\
\text { on hormone/peptide }\end{array}$ \\
\hline $\begin{array}{l}\text { Glucagon-like } \\
\text { peptide-1 (GLP-1) }\end{array}$ & $\begin{array}{l}\text { Enhances insulin secretion } \\
\text { Decreased glucagon secretion } \\
\text { Reduces hepatic gluconeogenesis } \\
\text { Delays gastric emptying } \\
\text { Satiety regulation }\end{array}$ & $\begin{array}{l}\text { Shown to reduce GLP- } \\
1 \text { secretion and } \\
\text { modulate sweet taste } \\
\text { sensitivity in mice }\end{array}$ \\
\hline Leptin & $\begin{array}{l}\text { Controls adiposity } \\
\text { Regulates energy intake by up- and } \\
\text { down-regulating neurons in the } \\
\text { ARC } \\
\text { Modulates mesolimbic } \\
\text { dopaminergic pathway involved in } \\
\text { reward-seeking behaviour of } \\
\text { appetite }\end{array}$ & $\begin{array}{l}\text { Correlation between } \\
\text { antipsychotic use and } \\
\text { high levels of leptin. } \\
\text { Believed to be due to } \\
\text { weight gain, rather } \\
\text { than a cause of weight } \\
\text { gain }\end{array}$ \\
\hline Ghrelin & $\begin{array}{l}\text { Effects on glucose and lipid } \\
\text { metabolism } \\
\text { Role in acid secretion and gastric } \\
\text { emptying } \\
\text { Induces hunger and increases food } \\
\text { intake }\end{array}$ & $\begin{array}{l}\text { Conflicting results - } \\
\text { some studies have } \\
\text { shown reductions, and } \\
\text { some have shown } \\
\text { increases in circulating } \\
\text { levels }\end{array}$ \\
\hline Insulin & $\begin{array}{l}\text { Largely involved in regulating } \\
\text { glucose homeostasis } \\
\text { Additionally, acts centrally in the } \\
\text { hypothalamus and modulates } \\
\text { dopaminergic reward associated } \\
\text { neurons to reduce appetite and } \\
\text { alter food preferences }\end{array}$ & $\begin{array}{l}\text { Antipsychotic } \\
\text { associated weight gain } \\
\text { can result in insulin } \\
\text { resistance. Further, } \\
\text { antipsychotics have } \\
\text { been shown to inhibit } \\
\text { peripheral and central } \\
\text { insulin action }\end{array}$ \\
\hline Melatonin & $\begin{array}{l}\text { Regulates circadian rhythm } \\
\text { Regulates body weight, glucose } \\
\text { and lipid metabolism } \\
\text { Synchronizes metabolism with rest } \\
\text { and activity }\end{array}$ & $\begin{array}{l}\text { Associated with } \\
\text { reduction in melatonin }\end{array}$ \\
\hline
\end{tabular}

Table 2: Summary of role of neuroreceptors in AIWG

\begin{tabular}{|c|c|c|c|c|}
\hline & \multicolumn{4}{|c|}{ Neuroreceptor } \\
\hline & D2 & 5-HT2C & 5-HT2A & H1 \\
\hline $\begin{array}{l}\text { Receptor } \\
\text { role in } \\
\text { metabolic } \\
\text { homeostasis }\end{array}$ & $\begin{array}{c}\text { D2 receptor } \\
\text { deficiency increases } \\
\text { reward-seeking } \\
\text { behaviour e.g. } \\
\text { increased food } \\
\text { intake and appetite } \\
\text { in obese individuals }\end{array}$ & $\begin{array}{l}\text { Expression of the } \\
5 \text {-HT2C receptor } \\
\text { on POMC and } \\
\text { NPY neurons in } \\
\text { the ARC. Inverse } \\
\text { agonism may } \\
\text { induce more } \\
\text { weight gain }\end{array}$ & $\begin{array}{c}\text { Neocortical } \\
\text { binding of 5-HT2A } \\
\text { has shown a } \\
\text { positive } \\
\text { correlation with } \\
\text { increased BMI }\end{array}$ & $\begin{array}{l}\mathrm{H} 1 \text { receptor } \\
\text { antagonism leads to, } \\
\text { greater activation of } \\
\text { hypothalamic AMP- } \\
\text { related kinase } \\
\text { (AMPK), which is } \\
\text { associated with } \\
\text { appetite stimulation }\end{array}$ \\
\hline
\end{tabular}


Table 3: Summary of genes frequently identified as contributors to AIWG

\begin{tabular}{|c|c|c|}
\hline Genes involved in AIWG & Responsible for encoding & SNPs reported in literature \\
\hline HTR2C & $\begin{array}{l}\text { Serotonin } 2 c \text { receptor } \\
(5 \mathrm{HT}-2 \mathrm{c})\end{array}$ & $\begin{array}{l}\text { rs3813929 } \\
\text { rs6318 } \\
\text { rs518147 } \\
\text { rs381328 }\end{array}$ \\
\hline DRD2 & Dopamine 2 receptor & $\begin{array}{l}\text { rs1799978 } \\
\text { rs7131056 } \\
\text { rs6275 } \\
\text { rs2242591 } \\
\text { rs1079598 }\end{array}$ \\
\hline ADRA2A & Alpha 2a receptor & rs1800544 \\
\hline GNB3 & $\begin{array}{l}\text { Guanine nucleotide- } \\
\text { binding protein beta } \\
\text { subunit }\end{array}$ & rs5443 \\
\hline MC4R & Melancortin 4 receptor & $\begin{array}{l}\text { rs17782313 } \\
\text { rs489693 }\end{array}$ \\
\hline FTO & $\begin{array}{l}\text { Fat mass and obesity- } \\
\text { associated protein }\end{array}$ & rs9939609 \\
\hline LEPR & Leptin receptor & rs1137101 \\
\hline BDNF & $\begin{array}{l}\text { Brain-derived neurotrophic } \\
\text { factor }\end{array}$ & rs6265 \\
\hline INSIG2 & Insulin induced gene 2 & $\begin{array}{l}r s 10490624 \\
\text { rs17047764 } \\
\text { rs17587100 } \\
\text { rs7566605 }\end{array}$ \\
\hline SNAP25 & $\begin{array}{l}\text { Synaptosomal nerve- } \\
\text { associated protein } 25\end{array}$ & $\begin{array}{l}\text { rs1051312 } \\
\text { rs3746544 } \\
\text { rs8636 }\end{array}$ \\
\hline
\end{tabular}

*Table adapted from Malhotra (2016)

Table 4: Associated risk of weight gain with commonly prescribed SGAs

\begin{tabular}{|l|l|}
\hline Antipsychotic & $\begin{array}{l}\text { Risk to induce weight } \\
\text { gain }\end{array}$ \\
\hline Amisulpride & Intermediate \\
\hline Aripiprazole & Low \\
\hline Brexipiprazole & Low \\
\hline Cariprazine & Low \\
\hline Clozapine & High \\
\hline Lurasidone & Low \\
\hline Olanzapine & High \\
\hline Quetiapine & Intermediate \\
\hline Risperidone & Intermediate \\
\hline Ziprasidone & Low \\
\hline
\end{tabular}

